\title{
Thinking on the Inheritance and Development of Central Plains Culture
}

\author{
Li Xinyu \\ Henan University of Animal Husbandry and Economy, Zhengzhou, Henan, 450000
}

Keywords: Central Plains culture; inheritance; development

\begin{abstract}
Looking at the current world pattern, the status of culture in the competition of comprehensive national strength in any country is increasing. In other words, whoever occupies the commanding heights of culture will be able to better grasp the initiative in the fierce international competition. "The Central Plains have won the world" shows that importance of the Central Plains culture is self-evident. The research on the inheritance and development of the Central Plains culture is focused on the meticulous research on the Central Plains culture, a scientific interpretation of the historical evolution of the specific culture of the Central Plains culture, and a positive analysis of the positive aspects of the Central Plains culture. Inheriting the core and essence of the cultural spirit of Central Plains can further promote the culture of the Central Plains, so that the Central Plains culture in the current society is radiating new vitality, get more extensive dissemination, in turn, also promote the further economic and cultural development of the Central Plains.
\end{abstract}

\section{Introduction}

The research on the Central Plains culture has also been published in recent years. For example, research on the Central Plains Yu Merchants Culture, the development of the Central Plains Literature, research on the writings of the Central Plains Writers, research on the creation of the Central Plains Writers Group, etc. Research on a specific aspect has not done enough research on the comprehensive inheritance and development of the Central Plains culture, and there is still much room for research [1].

China Central Plain Culture is a general term for material culture and spiritual culture based on the Central Plains region. It can be traced back to the Neolithic period from about $6,000 \mathrm{BC}$ to about 3,000 BC. The Central Plains region is the cradle of Chinese civilization. In the history of China, there were more than 20 dynasties successively located in the Central Plains region, thus forming a unique regional culture-Central Plains culture. [2] The Central Plains culture is an important source and core component of Chinese culture. In general, the Central Plains culture takes Henan Province as the core, with the majority of the middle and lower reaches of the Yellow River as the hinterland, and radiates outwards in layers, affecting overseas. Throughout history, the Central Plains region in ancient times was not only the political and economic center of China, but also the birthplace of mainstream culture and dominant culture. It has played a pioneering role in building the entire Chinese civilization system. It should be said that the Central Plains region has a long history of standing in the mainstream of orthodox Chinese history with a special geographical environment, historical status, and humanistic spirit. The Central Plains culture to some extent represents traditional Chinese culture.

\section{The Characteristics of the Central Plains Culture}

The characteristics of the Central Plains culture include roots, originality, inclusiveness, openness, and foundationality. The Central Plains culture has a beginning and a motherhood in the entire Chinese civilization system; it has played a pioneering role in building the entire Chinese civilization system; it is compatible with all kinds of goodness and unity; it absorbs a large amount of foreign culture; it is also strong. From the beginning of the Northern Song Dynasty, the Central Plains culture relied on the most advanced navigation technology at that time to sow the countries 
of South Asia and Africa, and opened up a new era for the propagation of world civilization. [4] The Central Plains culture is the main body and backbone of the Chinese culture system. The status, in the continuous integration and exchange with other cultures, has expanded continuously, giving rise to the formation of Chinese culture.

History, writing, language, thought, literature, diet, folk customs, etc. are expressions of Central Plains culture. For example, Central Plains Literature is the general source of Chinese literature. The proud historical facts such as "Hanwei Weiqiwen Luoyang" and "Luoyang Zhigui" have already been circulated as popular stories. Many famous literati in the dynasties have come from the Central Plains. In the late 19th century, the writer of the Central Plains in modern times was known as the "literary Heilongjiang" by the literary world. [4]

To sum up, the Central Plains culture as an important component has influenced the overall development and context of Chinese culture in many aspects. Under the present premise that Xi Xie proposed to realize the "Chinese Dream" at an early date, the Central Plains Culture Inheritance and development are worthy of continuous attention and research by our scientific researchers. The achievements of the inheritance and development of the Central Plains culture will also bring about multi-dimensional value to the further rise of the Central Plains.

\section{The Heritage of Central Plains Culture}

How to subserve the Central Plains culture and how to promote the spread of the Central Plains culture under the current social conditions, so as to further develop the Central Plains culture has made research related to the actual, this will be a more important research point that fits the economic and cultural development of the Central Plains region. The research process can be roughly carried out as follows:

First, it emphasizes the inheritance and development of the specific culture form of the Central Plains culture, explores the law of inheritance and development of the Central Plains culture; Second, it explores the core and essence of the cultural spirit of the Central Plains in order to further develop the Central Plains culture.The third is to explore how to better achieve the heritage of the Central Plains culture, how to promote the culture of the Central Plains under the current social conditions.[4]

Central Plains is a relative regional concept based on Henan Province, including the middle and lower reaches of the Yellow River, such as Henan, Shaanxi, Shanxi, Anhui, Hubei, Shandong, and even a small part of northern Hunan. Because of its geographical location, the Central Plains is located in China and is a political and economic center. The importance of the Central Plains culture has thus been demonstrated. However, in the ancient times, the Central Plains culture was profound and far-reaching. It is not the reason why we can sit and watch our minds and rest on our laurels. We should consider how to inherit and develop the culture of the Central Plains in the current era of cultural rejuvenation, respond to the call of the Henan provincial government, and put the image of Henan province as a big agricultural province. Promote to a strong cultural province, use the energy and inner potential of the Central Plains culture to boost the "rise of the Central Plains"[5].

The culture of the Central Plains is a major part of the Yellow River culture. The root culture, the Yellow Emperor culture, the Heluo culture, the Shaolin culture, the Ding culture, the Tai Chi culture, etc. are all strong and invaluable chapters in Chinese culture. Therefore, the Central Plains culture is a concept of pluralism that is continuously generated and grown. The stability of the cultural spirit of the Central Plains also has a variety of complex orientations.

The Central Plains culture needs more attention in the new era of the strategy of strengthening the province of culture, playing its positive role, and tapping harmonious cultural resources. Henan's rich cultural resources are very important for developing the cultural industry and enhancing the strength of cultural development.

The foundation of the Central Plains culture is the self-sufficient lifestyle of the agricultural society. The traditional culture of the Central Plains emphasizes generosity, moderation, harmony, and pragmatism. It attaches great importance to family traditions, filial piety, and affection, which is inconsistent with the social governance spirit of the current social governance and the rule of law. 
With harsh conditions and unsatisfactory natural environment, the Central Plains people have longed for stability and pursued harmony. "The sky is strong and the gentleman strives for self-improvement," but this also creates many people who are poor, rest on their laurels, and are backward and foolish without knowing themselves; and " The moral preaching of the heavenly nature and exterminating desires suppressed the vitality of economic and social development. The cultural concept of "heavy earth and relocating" also made the Central Plains culture as a whole tend to be simply closed.

The process of "Rise of Central China" should be a process of vigorous development in Henan Province and a process of Henan's cultural efforts. We must vigorously create the cultural image of Henan Province, enhance the cultural soft power of our province, and strengthen the close relationship between culture and economy. [6] The rejuvenation of the Central Plains culture should be closely related to economic construction, political construction, ecological environment construction, and the construction of a harmonious society.

The Central Plains culture should condense history and connect the future, providing better reference to the cultural soft power of the Henan economy and society that entered the historical period of key development, prospering the development of the Central Plains culture, and providing a powerful impetus for the great historical process of the rise of the Central Plains.

For example, the development of cultural and creative industries, tourism development of the theme culture, the construction of the book resources of the Central Plains culture, how to rebuild the Central Plains Cultural Center, how the modernization of the Central Plains culture, the internal mechanism of the culture of rituals and music, and how to rationally use, Confucian culture and Associations between historical and cultural celebrities... Such research initiatives should be led by specialized R\&D institutions in the strategy of a strong province of culture to identify key operating points for improvement and operation, enhance cultural awareness, and take seriously local and Central Plains culture continuously improve the ability to build advanced socialist culture [6].

\section{Development of Central Plains Culture}

Based on these considerations, we mainly focused on the collection of books on the original culture in the study of the topic. We discussed the core spirit and values of the Central Plains culture in the study, looked for historical changes in the cultural spirit of the Central Plains, explored the development strategy of the Central Plains culture in the new period, and tried our best to tap the potential of the Central Plains culture and strive to enhance the attractiveness and competitiveness of the Central Plains culture in carrying forward and spreading the Central Plains culture in the new era.

If the outward development of the Central Plains culture is called a layered structure, it can be used to describe how the regional culture stepped out of its inherent boundaries step by step, shifting it to Chinese culture. Correspondingly, Fei Xiaotong's "snowball" theory not only explains the historical formation of the Chinese nation, but also heralds this nation as a cultural complex centered on the Central Plains of the middle and lower reaches of the Yellow River.[7] The Chinese national spirit is the gradual sublimation and improvement of the traditional values of the Central Plains. Thus, if we say that the cohesiveness of the Chinese nation comes from the constant retrospection and recollection of its own history, the Central Plains culture is undoubtedly the main object of this recollection. It has both original and dominant significance both for Chinese culture and for the Chinese national spirit.

Of course, from a historical point of view, the Central Plains culture is not a constant cultural element, but like the Chinese culture and the Chinese national spirit, it has its continuous formation process and the diversity of its contents. In the ancient times, Yandi and Huangdi tribes merged to lay the embryonic form for the Chinese nation. This means that the Central Plains nation and culture were diverse at the beginning of their formation. Later, the conflicts between the East and the West tribes at the time of Yin Zhou, the contending in the Warring States period, the Eastern Buddhism in the Eastern Han Dynasty, the national integration in the Southern and Northern Dynasties, and the mass migration in the Northern and Southern Dynasties during the Song and 
Yuan Dynasties all determined the nationalities and culture that the Central Plains culture relied on. The heterogeneity of the ingredients, that is, the historical form of the Central Plains culture is not so much a free entity. Rather, it is a unity in which various ethnic groups and cultures continuously enter into, continue to meddle in and continue to be creatively reconstructed. In this process, different nationalities were transformed into Central Plains due to "embarking on the Central Plains" or "entering the Central Plains," and different cultures were absorbed in the collision with the Central Plains culture and became an integral part of it. At the same time, some ethnic groups in the borderlands, even if they did not directly demonstrate their presence and strength in the Central Plains region, they often have a common history due to various contacts (such as war, trade, kinship, and tribute) established with the Central Plains dynasty. Memory, with a common area of spiritual backtracking. It can be considered that a cultural history of Central Plains is a hybrid history of various ethnic groups and diverse cultures. The Central Plains culture is also the common spiritual heritage of all ethnic groups in China because of its multiple internal structures. It is a common historical memory of the Chinese nation because of its integration in the integration. According to this, if the Chinese national spirit is said to be a spirit united by common historical memories, then the Central Plains culture undoubtedly played an irreplaceable role in the formation of this spirit[7].

\section{The Significance of Cultural Development in Central Plains}

Based on the above judgments, it is of great theoretical significance to study the historical formation of the Chinese national spirit from the perspective of the Central Plains culture. Mainly in the following three aspects:

(1) The dominance of the Central Plains culture in the formation of the Chinese culture and the Chinese national spirit has made the study of the Central Plains culture the groundwork for the study of the Chinese national spirit. This foundational nature means that we can provide a historical and logical explanation for the Chinese culture and the Chinese national spirit through the study of the Central Plains culture. As far as history is concerned, Chinese culture is a culture originating from the Central Plains. Studying this culture is helpful to grasp the positive pulse of Chinese culture and the spirit of the Chinese nation and provide a clear clue for its follow-up development. Logically speaking, as a "childhood" of Chinese culture, Central Plains culture is characterized by its geographical and production methods, which, to a certain extent, determines the characteristics of later Chinese culture and Chinese national spirit. Only by first understanding the ideas and values that this culture has formed at its origin can we find an exact theoretical starting point for the study of Chinese spirituality. At the same time, the history of Chinese culture is not only an ever-expanding history of Central Plains culture, but also a history of continuous return to the values it has provided. This kind of retrospection makes the core values of the Central Plains culture continue to be revisited by later generations, making it a spiritual condensation point that sustains the continuity and internal unity of Chinese history[8].

(2) The Central Plains culture is an ever-growing concept. Its development provides a concise paradigm and clue for understanding the history of Chinese culture. As mentioned above, the origin of the Central Plains culture can be traced back to the conflicts and integration of the two major clan tribes in ancient Yanhuang, followed by the conflicts between the two cultures of Yin Zhou, the debates in the Warring States Period, the eastward transmission of Buddhism in the Eastern Han Dynasty, and gradual localization. From this point of view, the Central Plains culture has both the stability of the value concept and the diversity of the internal composition. The pluralistic characteristics of this cultural element have made the Central Plains cultural studies rich in content. Even the history of the Central Plains culture is a brief history of Chinese culture. At the same time, from a historical point of view, the diversity of the internal composition of the Central Plains culture is a multivariate dominated by one dollar. This "one dollar" is the basic values that have been laid in the Spring and Autumn and the Warring States period. Its history of development is a multicultural element that continues to this core value. The history of polymerization.

(3) The study of the Central Plains culture is conducive to a deeper understanding of the modern destiny of Chinese culture and the importance of renewing the Chinese national spirit. The Central 
Plains culture developed into the most mature form in the Song Dynasty and then declined. This is related to the shift of China's political, economic, and cultural centers after the Yuan and Ming dynasties. It is also related to the strong invasion of Western cultures in the modern era. Especially after the May 4th Movement, the intervention of heterogeneous culture made traditional Chinese culture the object of critical reflection. This fundamental point of criticism and reflection is the basic values of the Central Plains culture[8].

\section{Conclusion}

Since the new period, with the continuous development of the socialist market economy, the Central Plains culture based on traditional agricultural production methods has increasingly exposed its limitations. It can be argued that the difficult transition of Chinese society from modern times to modern civilization is consistent with the difficulties encountered in today's transition from the agricultural production mode of the Central Plains to modern times. From this point of view, the Central Plains region, as one of the most stubborn regions in China's traditional production methods and cultural characteristics, will be able to successfully transition to modernity and will have a landmark significance in evaluating the overall modern path of Chinese society. Or, to understand the modern destiny of the Central Plains culture provides a template for understanding the modern destiny of Chinese culture.

\section{Acknowledgement}

This article is the result of the Key Scientific Research Projects of Colleges and Universities in Henan Province "Management Practice and Research of Newly-Enrolled Colleges and Universities" (Subject No. 17A880008).

\section{References}

[1] Wang Hao. Establishing "Cultural Confidence" of Literature in Inheritance and Innovation: A Survey of the Relationship between Contemporary Chinese Literature and Outstanding Traditional Culture [J]. Chinese Social Sciences, 2017(11).140-150.

[2] Li Xin. Building the Central Highlands of Culture and Building a Strong Central Plains Culture City [N]. Xuchang Daily, 2017-08-09(004).

[3] Chen Linjing. On the Spread of Central Plains Culture under the Background of "All People Reading" [J]. Appreciation of Famous Works, 2017(17).108-110.

[4] Sun Wenjie. The path of the promotion of the original culture in the "Internet+" era[J]. Young Journalist, 2017(14).28-29.

[5] Xinyu Li. A Study on the Characteristics and Transmission Ways of China Central Plain Opera Culture[A]. Research Institute of Management Science and Industrial Engineering. Proceedings of 2017 2nd International Conference on Education, Sports, Arts and Management Engineering (ICESAME 2017) [C]. Research Institute of Management Science and Industrial Engineering:2017.4.

[6] Wu Tao. The Carrier of the Culture of the Central Plains[J]. Journal of Luoyang Teachers College, 2017,36(03).30-37.

[7] Zheng Jingjing. Research on the excellent traditional culture connotation of Chinese socialist core values[D]. Dalian Maritime University, 2017.

[8]. Opinions on Implementing the Inheritance and Development Project of the Excellent Chinese Traditional Culture [N]. People's Daily, 2017-01-26(006). 